\title{
Representações da docência na imprensa pedagógica na Corte imperial (1870-1889): o exemplo da Instrução Pública
}

\author{
Alessandra Frota de Schueler
}

Universidade do Estado do Rio de Janeiro

\section{Resumo}

0 presente trabalho visa analisar as representações da docência veiculadas por meio da imprensa pedagógica na Corte imperial, entre as décadas de 1870 e 1880, tomando como base da pesquisa documental alguns artigos publicados por professores primários no periódico Instrução Pública. Objetiva-se, ainda, perceber como, mediante esse processo de construção e reelaboração de representações e identidades, os professores apresentaram-se como categoria profissional ao público leitor, ora por vias diretas, como nos exemplos e nas trajetórias pessoais que analisavam, ora por meio de temas diversos, ao abordarem os problemas educacionais e sociais que julgavam fundamentais.

A imprensa pedagógica constitui instância privilegiada para a compreensão dos modos de funcionamento do campo educacional. Na revista, podemos encontrar informações e representações sobre o trabalho docente, as práticas pedagógicas e as demandas da categoria do magistério. Assim, é possível apreender os conflitos e as disputas no interior dos grupos de professores, bem como as representações então construídas a respeito da profissão docente.

Com isso, defende-se que os mestres das escolas primárias da Corte participaram ativamente no processo de constituição da profissão docente, fazendo-se professores por meio da discussão pública e da produção coletiva de identidades profissionais, sempre provisórias, móveis e contraditórias que, porém, funcionavam como instrumento de agregação em torno da configuração da idéia do magistério como uma missão de fundamental função social e pública.

\section{Palavras-chave}

Imprensa pedagógica - Representações da docência - Profissionalização docente - História da educação.

Correspondência:

Alessandra Frota de Schueler

Rua Tupiniquins, 305

24360-260 - Niterói - RJ

e-mail: alessandrafrota@hotmail.com 


\title{
Representations of teaching in the pedagogic press at the Imperial Court (1870-1889): the case of the Instrução Pública
}

\author{
Alessandra Frota de Schueler \\ Universidade do Estado do Rio de Janeiro
}

\begin{abstract}
The present work analyzes the representations of teaching publicized by the pedagogic press at the Imperial Court between the 1870s and the 1880s, taking as the basis for its documental research articles published by primary teachers in the journal Instrução Pública (Public Instruction). The text also wants to reveal how, through this process of construction and re-elaboration of representations and identities, the teachers presented themselves to the readers as a professional category, sometimes directly, as in the personal examples and trajectories they analyzed, sometimes through various issues, when they dealt with social and educational problems they regarded as fundamental.

The pedagogical press is a privileged instrument to understand the workings of the educational field. In that journal we can find information and representations about the teaching profession, the pedagogical practices, and the demands of the teaching professional category. It is thus possible to appreciate the conflicts and disputes inside the groups of teachers, as well as the representations then constructed about the teaching profession.

With that, the text proposes that the primary school teachers at the time of the Imperial Court participated actively in the process of construction of the teaching profession, becoming teachers through the public discussion and the collective production of professional identities. Identities that were always provisional, mobile and contradictory, but which functioned, nevertheless, as instruments of union around the definition of the idea of teaching as a mission of fundamental social and public significance.
\end{abstract}

\section{Keywords}

Pedagogic press - Representations of teaching - Professionalization of teaching - History of education.

Contact:

Alessandra Frota de Schueler

Rua Tupiniquins, 305

24360-260 - Niterói - RJ

e-mail: alessandrafrota@hotmail.com 


\section{A imprensa pedagógica: o exemplo da Instrução Pública}

A historiografia da educação, enfatizando a materialidade de práticas sociais educativas, a constituição dos saberes e da formação docente, vem recentemente demandando a utilização de novos documentos. Novas formas de olhar e abordar as fontes também foram responsáveis pela atenção que os textos impressos e os jornais vêm adquirindo na pesquisa histórica da educação, que alarga seus interesses para as práticas culturais, os sujeitos históricos e os produtos culturais (Souza; Catani, 1998).

A imprensa pedagógica especializada no debate de assuntos e problemas educacionais constitui instância privilegiada para a apreensão dos modos de funcionamento do campo educacional, pois fazem circular informações sobre o trabalho docente, as práticas pedagógicas, as reivindicações da categoria do magistério, permitindo conhecer as lutas por legitimidade que se travam no interior do campo, bem como as representações construídas a respeito da profissão docente (Nóvoa, 1993; Catani; Bastos, 2002).

0 surgimento da imprensa especializada em educação, elaborada e publicada por membros atuantes ou envolvidos com o magistério, público ou particular, visando atingir basicamente professores e professoras, autoridades de ensino, os pais e as famílias dos alunos, ao que parece, no caso da Corte, teve de esperar o alvorecer da década de 1870 . Sem dúvida, o processo de estatização da profissão docente e a afirmação dos professores como classe profissional definiram os rumos do surgimento da imprensa pedagógica na cidade do Rio de Janeiro.

Para Heloísa Villela (2001), fundamentando-se nas análises de Antonio Nóvoa (1987, 1993), a emergência da imprensa e as tentativas de agregação coletiva em associações indicam a existência de uma tomada de consciência, por parte dos mestres-escolas, de seus interesses como grupo profissional, a despeito das identidades e experiências individuais diversas; de sua composição heterogênea e das diferenças socioculturais de seus elementos; das divergências a respeito dos múltiplos significados possíveis de educação e de instrução primárias; das distintas representações, apropriações e práticas; dos sentidos e das funções atribuídas ao ser professor e professora.

Nesse esforço coletivo dos professores e professoras rumo à associação e à organização como grupo profissional, estavam em causa tentativas de construção e de afirmação de identidades - sempre provisórias, fluidas e mutáveis, porque históricas -, em meio às contradições, ambigüidades, diversas práticas e representações da profissão e múltiplas e multifacetadas experiências docentes que os professores, individualmente, elaboraram (e reelaboravam) e vivenciaram. Como salientou Nóvoa (1992), a identidade docente, considerada tanto nos seus aspectos individual e coletivo, não é um dado adquirido, não é uma propriedade inerente ao domínio de um profissional ou de um grupo determinado. Ao contrário, a identidade docente é um processo, posto que constitui um lugar de lutas, um espaço de construção de maneiras de ser e de estar na profissão.

Esse processo de construção e de reconstrução permanente de identidades docentes integra os processos históricos de constituição e de transformação da própria profissão docente, ao passo que configura uma faceta do complexo fazer-se ${ }^{1}$ dos professores e professoras primárias, explicitando um avanço significativo no movimento oitocentista de profissionalização da carreira docente.

A imprensa pedagógica constituía, portanto, um dos veículos de comunicação e de debates entre os professores, as autoridades administrativas e as famílias, para além de significar um trabalho de reunião e agrupamento de diferentes membros do magistério, contribuindo para a consolidação de um sprits de corps, ainda que condensasse divergências, conflitos e embates internos aos grupos e associações de

1. Para Edward Thompson (1987), a expressão fazer-se está relacionada à própria constituição de um grupo, pois, ao mesmo tempo em que demonstra a sua complexidade, realça a participação ativa dos sujeitos nesse processo. 
professores, o que ficou evidenciado até mesmo pela existência de diversas publicações pedagógicas que polemizavam entre si, disputando a hegemonia na definição de rumos para a constituição da docência.

Nesse diálogo, iniciado e travado tanto interna (entre si, no processo de fazer-se) quanto externamente (com o Estado e a sociedade carioca), os grupos de professores públicos discutiram não apenas diversas questões relativas propriamente ao ensino - como o direito à instrução pública primária, os significados da escola para educação popular, o funcionamento e a modernização das escolas, as condições de trabalho docente, os novos métodos pedagógicos, os objetivos do ensino, o público-alvo das escolas, as disciplinas escolares -, mas sobretudo realizaram debates e propuseram saídas para buscar solucionar uma série de problemas, que identificavam como as "urgentes questões sociais" e educacionais de seu tempo (Schueler, 2002, p. 248).

Esse foi o caso do periódico Instrução Pública: Publicação Hebdomadária, redigida por um grupo de professores públicos primários da Corte imperial, que surgiu em meio aos debates sobre as reformas educacionais e os diálogos então abertos entre os professores e o Estado imperial, nove meses depois do polêmico Manifesto dos Professores Primários, assinado pelo professor Manoel José Pereira Frazão, em nome de outros 35 docentes. Em uma manhã de domingo, 13 de abril de 1872, colocava na rua o seu primeiro número, editado pelas oficinas da tipografia Cinco de Março, então localizada no número 59 da Rua da Ajuda.

A composição da revista, no que se refere aos seus editores, foi amplamente divulgada ao público. Por meio das indicações encontradas, percebe-se que o periódico constituiu mais uma das estratégias utilizadas por agentes do governo e por alguns professores públicos para encurtarem e viabilizarem o diálogo, visando debater os problemas da educação pública. Tanto é assim que, entre os proprietários do periódico, estava nada mais nada menos o Secretário de Instrução Pública da Corte, Theófilo das Neves Leão. 0 redator-chefe da revista, o bacharel em Direito pela Faculdade de São Paulo, Dr. Alambary Luz, era também um agente do governo que, embora não remunerado, contava com o privilégio de ocupar o distinto cargo de Inspetor de Distrito, responsável pela fiscalização das escolas públicas e particulares da Freguesia de Paquetá. Além desse cargo, nos anos de 1860, Alambary Luz ocupou importantes posições públicas no governo provincial fluminense, notadamente na Diretoria de Instrução Pública e na Escola Normal de Niterói. As relações dos editores com as autoridades da Inspetoria Geral de Instrução, órgão responsável pela gestão dos negócios da instrução primária e secundária na Corte eram evidentes, o que facilitou a percepção de apoio financeiro para a publicação, além da garantia de subscrição oficial dos números do periódico para a distribuição gratuita entre os professores da cidade (Villela, 2001).

Em relação aos professores públicos primários envolvidos na direção e na redação do periódico, encontramos nomes que se tornaram recorrentes nos anos de 1870 e 1880: Antonio Estevam da Costa e Cunha, divulgador do original e nacional método de leitura Bacadafá, e seu pai, Antonio Severino da Costa; Thereza Leopoldina Araújo; Augusto Candido Xavier Cony², defensor dos Asilos Infantis para educação de crianças pobres, livres e libertas; Carlos Brazil; Manoel Olympio da Costa; Francisco da Silva Castilho, um dos mais antigos professores públicos da Corte e elaborador de cartilhas e gramáticas da Língua Portuguesa, além de compêndios de instrução religiosa, utilizados nas escolas primárias e secundárias do lmpério.

\section{Representações da docência: forjando identidades docentes}

A Instrução Pública, ao ser organizada como um periódico semanal destinado à discussão pública das temáticas e dos problemas edu-

\footnotetext{
2. Augusto Candido Xavier Cony foi professor público de instrução primária na Freguesia de Santana, na Corte, tendo ainda mantido escola particular própria. Redigiu com Antonio Estevam Costa e Cunha a Instrução Pública.
} 
cacionais e escolares, entre os professores da Corte e as autoridades do governo imperial, tinha como objetivo central a afirmação da necessidade inadiável de promoção do ensino primário como instrumento não apenas de alfabetização, mas sobretudo de educação popular por excelência. A assertiva segundo a qual a instrução primária, mais do que uma necessidade para o Estado, consistia um direito do cidadão, garantido pela Constituição de 1824, não era rara nas páginas e nos discursos dos seus redatores nos primeiros anos de publicação da revista.

Uma outra preocupação relevante, verificada na leitura dos artigos, é a perseguição de um outro objetivo, em tudo relacionado ao primeiro: a consolidação social do professor como agente fundamental da civilização e do progresso social e nacional. A busca do reconhecimento público da importância da educação era um outro modo de mostrar a própria afirmação dos professores como classe de funcionários indispensáveis à reconstrução da nação e à obra de elevação do Império e do povo ao patamar das nações ditas civilizadas. 0 professor primário, braço direito do Estado na tarefa de educar e instruir os cidadãos, deveria então ocupar lugar de destaque na sociedade imperial.

As tentativas de solidificação da figura do professor como artífice fundamental para o progresso social, e então com ampla participação das mulheres na educação das crianças, produziam uma série de discursos, visões e representações do ser professor, dos papéis desempenhados pelos membros do magistério em suas práticas sociais cotidianas no momento em que viviam, escreviam e lutavam por seus próprios interesses e projetos de sociedade. Relatos sobre a missão crucial dos mestres na formação da cidadania abundavam, assim como eram recorrentes as narrativas queixosas sobre as dificuldades, a precariedade das condições materiais e o abandono do governo para com a instrução pública e os mestres-escolas.

A relação do ofício de mestre e a pobreza dos seus membros foram reiteradas em vários discursos e falas dos próprios professo- res. Apenas para destacar algumas referências, basta citar a reflexão realizada por Antonio Candido Xavier Cony sobre a filiação dos professores ao povo - eram "filhos do povo" e, como tais, a educação era a sua herança, única que, por sua vez, deixariam para seus descendentes. As queixas de Alambary Luz, nos inúmeros Editoriais, também deixavam claro a exigüidade dos salários pagos pelo governo aos professores das escolas públicas primárias, fato agravado pelo desconto dos aluguéis das casas escolares em seus vencimentos e a pobreza dos recursos pedagógicos e materiais das casas escolares $^{3}$.

Em torno da construção de representações sobre os professores e as suas práticas cotidianas, suas condições de trabalho e suas possiveis experiências sociais nas escolas públicas primárias, a Instrução Pública dedicou muitas de suas páginas e deu espaço para a narrativa de alguns mestres em seu próprio nome que, por meio de artigos, deixaram registros sobre o que pensavam sobre o seu ofício e sobre as situações vivenciadas nas escolas primárias da cidade do Rio de Janeiro nos anos de 1870.

Para alguns, os professores, como os alunos, eram filhos do povo. 0 seu trabalho como educadores seria a única herança legada aos seus filhos, dizia Cony. Ter a educação como herança aos filhos constitui uma expressão que nos indica algumas possibilidades de leitura. De um lado, pode ser interpretada como a afirmação, a valorização e a reprodução do ensino no interior das famílias de professores e o papel destes como os primeiros instrutores de seus próprios descendentes. 0 que resultava, não raro, em um estímulo para que se reafirmasse a reprodução endógena do ofício de mestre-escola, pois, ao que tudo indica, havia uma tendência de transmissão dos

3. A respeito dos aluguéis das casas escolares, da ausência de edifícios escolares e do público que freqüentava a instrução primária pública, conferir: "Extrato do Relatório de José Bento da Cunha Figueiredo, Inspetor Geral de Instrução da Corte". Instrução Pública, Ano I, n. 21, 01/09/1872. 
saberes e práticas da profissão docente dos pais aos filhos e/ou sobrinhos e agregados - e dos professores catedráticos das escolas para os adjuntos, muitas vezes, estes próprios, filhos e parentes dos efetivos (Schueler, 2002).

As representações da educação, como a única herança deixada aos filhos, também auxiliavam os professores na construção de imagens de austeridade e esforço pessoal no interior de uma sociedade liberal e meritocrática, na qual, pela via da instrução e da educação, era possível aos individuos valerem-se de estratégias que os movimentasse por meio das hierarquias e no interior das diferenças socioculturais, alcançando posições intermediárias como as dos professores públicos. Estes, ainda que vinculados aos setores sociais empobrecidos, possuíam o prestígio e a distinção que a sua importante função social lhes proporcionava. Ambigüidade que seria característica da profissão docente no decorrer de sua constituição como carreira vinculada ao Estado.

Por isso, ter a educação como única herança aos seus descendentes implicava, em outro sentido, a manutenção dos professores, mesmo depois de funcionarizados e vinculados ao Estado, em extratos sociais inferiores, o que estava expresso, em última instância, nos vencimentos anuais percebidos pelos professores públicos primários, equiparados aos salários de algumas categorias de artesãos e trabalhadores manuais qualificados e/ou aos de outros empregados do baixo escalão da burocracia imperial.

Esses temas eram mais explicitados quando Alambary Luz e os redatores abordavam a questão da formação profissional dos mestresescolas, então definida pela ausência, pela falta, pelos silêncios e lacunas das autoridades. Em novembro de 1872, ao enfocar o tema Escola Normal, Alambary Luz traçava um perfil dos homens e das mulheres que se dedicavam ao ensino das primeiras letras no Império brasileiro. Segundo ele, a carreira do magistério era, fundamentalmente, uma carreira de pobres. Os meninos pobres, distinguidos nas tarefas escolares, em geral concluindo os estudos primários aos 12 ou 13 anos de idade, tornavam-se professores adjuntos das escolas públicas, auxiliando o efetivo na instrução. A reprodução do magistério fazia-se, então, no interior das próprias escolas. Sem poder dispensar o salário, pela dependência do trabalho, os professores adjuntos não tinham condições de aprimorar os estudos e freqüentar a Escola Normal para completar sua formação profissional - o que explicava, na perspectiva de Luz, a baixa matrícula naquela instituição na capital da Província. A sugestão proposta pelo bacharel era simplesmente obrigar, por via de lei, os alunos-mestres a matricularem-se nas escolas que dirigiam.

Problemas na Escola Normal à parte, o fato é que a reclamação do redator-chefe reiterava a visão dos professores públicos como sujeitos oriundos das classes mais pobres da sociedade, formados por ofício na aprendizagem cotidiana com os mestres e no interior da corporação escolar. Na idade de 12 ou 13 anos, os meninos e as meninas tornavam-se adjuntos e ingressavam na experiência do magistério, profissão com a qual ganhariam um salário. A “carreira de pobres" era então uma necessidade, antes de ser uma vocação ou mesmo de exigir uma formação profissional científica e especializada ${ }^{4}$.

Com essa mesma linha argumentativa, o professor da Escola Pública de meninos da Freguesia do Espírito Santo, Carlos Brazil, já havia publicado, antes do redator-chefe, um artigo intitulado Reclamações em 30/06/1872. Suas queixas dirigiam-se prioritariamente ao Ministério do Império, particularmente à Inspetoria de Instrução Pública da Corte, mas também incluíam o próprio redator-chefe da Instrução Pública, o bacharel Alambary Luz.

De acordo com Brazil, os professores públicos da cidade eram indivíduos pobres, formavam-se no interior das escolas, primeiramente como adjuntos e, depois de efetivados, continuavam a receber parcos salários anuais ${ }^{5}$.

\footnotetext{
4. "A Escola Normal". Instrução Pública, Ano I, 17/11/1872, p. 282. 5. "O Ensino Oficial no Município Neutro". Instrução Pública, Ano I, 30/06/1872, p. 89-90.
} 
Em vista dos baixos salários que percebiam, Brazil, em nome de sua classe, respondia às críticas que constantemente recebiam os professores, por parte das autoridades, a respeito de seu suposto despreparo, decorrente de uma precária e mesmo de nenhuma formação pedagógica específica ao exercício da profissão ${ }^{6}$.

As reformas do ensino eram legítimas e, por isso mesmo, apoiadas pelos professores como absolutamente necessárias. Porém, as lamúrias pelo estado desanimador da instrução primária e os problemas enfrentados nas escolas não poderiam apontar para a responsabilização exclusiva dos mestres-escolas, tratando-os como réus, mártires do fracasso. Ao contrário, na opinião de alguns professores primários, como Brazil e Francisco Castilho, aos mestres não faltavam bons métodos pedagógicos, aptidão para ensinar ou capacidades técnicas ${ }^{7}$.

Como era mais fácil julgar do que fazer as mudanças necessárias, o professor Francisco Castilho respondia às críticas feitas ao magistério pelos Ministros que, a todo o momento, reclamavam da ausência de formação pedagógica dos mestres-escolas. Para o nosso professor, a questão era mesmo um problema de disputas em que as causas do atraso eram atribuídas de um lado a o outro. E o governo, muito naturalmente, "acreditando já ter se esforçado", colocava na atuação e nas pessoas dos mestres - a suposta falta de métodos modernos de ensino - a culpa pelo fracasso escolar na cidade. Também, igualmente de forma natural, dizia Castilho, os professores, na lida do seu cotidiano de trabalho, apontavam ao governo outras causas para que o progresso da instrução pública estivesse desgastado. A principal delas era óbvia: a deficiência da remuneração pecuniária, nas palavras textuais do mestre ${ }^{8}$.

A despeito das opiniões dos professores - que, quase por unanimidade, apontavam em direção à penúria das casas escolares e dos vencimentos, às origens pobres e à via-crúcis para que os poucos meninos, aprovados com distinção nos Exames Públicos se tornassem adjuntos das escolas primárias -, havia contro- vérsias a respeito da distribuição dos cargos e da situação de muitos professores da Corte.

Em um artigo sobre os Exames, o professor Antonio Severino da Costa denunciava a prática corrente de "apadrinhamento" entre mestres e alunos:

0 artigo 35 do Regulamento de Instrução concede o título e vantagens de professor adjunto aos alunos maiores de 12 anos que forem aprovados com distinção nas escolas públicas.

Mas o desejo de arranjar um filho, um irmão, um sobrinho, um afilhado ou um protegido, a indole compassiva, bondosa e condescendente do brasileiro, tem dado lugar a abusos que nem sempre tem sido corrigidos pelos três exames que o adjunto ainda fica sujeito e, a alguns, tal proteção ou 'felicidade' os acompanha, que chegaram até no santuário do magistério, desconhecendo a importância de seu sacerdócio. ${ }^{9}$

Contava, ainda, o professor Costa que uma professora pública enviou seu sobrinho à escola de um colega, pedindo-lhe que não o deixasse "junto com os outros" alunos, dispensando-lhe especial atenção para que alcançasse a aprovação "com distinção" nas matérias de ensino primário. Como o colega não atendera a seu pedido, a dita professora procurou atingir seu intento em outra escola da cidade e, mediante "barganha eleitoral", teria conseguido que

6. Consultar também: "Confederações Pedagógicas". Instrução Pública. Ano II, n. 13, 30/03/1873.

7. "Ao Sr. Alambary Luz. Consideracões de um Professor Público acerca da Instrução Pública". Francisco da Silva Castilho. Instrução Pública, Ano I, 26/06/1872, p. 99-101.

8. Outra causa para o "atraso" do ensino na Corte foi apontada pelo professor Antonio Severino da Costa: a falta de remuneração aos delegados e inspetores da instrução pública na cidade. 0 cargo, "honroso e respeitável", era oferecido a advogados e funcionários públi$\cos$, os quais precisavam dedicar-se a seus afazeres, alheios às tarefas de fiscalização. Costa defendeu a remuneração dos delegados e alegou que os cargos deveriam ser oferecidos aos párocos, os quais seriam responsáveis pela educação moral e religiosa das crianças. "Os delegados, a Inspetoria Geral e o Governo". Antonio S. da Costa. Instrução Pública. Ano I, 12/09/1872, p. 210.

9. "Os Exames nas Escolas Públicas". Instrução Pública. Ano I, 21/07/ 1872, p. 119. 
seu pupilo recebesse os "louvores" e as "distinções”, o que lhe propiciou assumir o cargo de professor adjunto na escola pública.

As vagas de adjuntos, pelo que se apreende da denúncia de Antonio da Costa, nem sempre cumpriam a reza liberal do mérito e da distinção pessoal dos alunos das escolas. Os arranjos políticos para nomear familiares, parentes e afilhados, não poucas vezes, garantiriam aos privilegiados e protegidos um lugar de adjunto nas escolas públicas primárias. 0 próprio Antonio Severino da Costa, que assinava a crítica ao recrutamento político dos docentes, como já foi visto, apresentou várias solicitações ao governo para que seus filhos fossem nomeados adjuntos. De fato, nas décadas de 1870 e 1880, conseguiram vagas no magistério público primário três dos descendentes desse professor: Antonio Estevam da Costa e Cunha, seu colega de redação na revista pedagógica, Eudóxia Brazilia da Costa e Jorge Eduardo da Costa ${ }^{10}$.

A trajetória de muitos professores e professoras públicas da Corte confere com as suas alegações de que a reprodução do magistério se dava no interior das próprias escolas, por meio dos adjuntos. 0 mesmo ocorre em relação às suas afirmações sobre a passagem do ofício de pais para filhos. É comum encontrarem-se maridos e esposas professores com filhos nomeados adjuntos nas escolas públicas ${ }^{11}$. No entanto, é preciso considerar que o fato de existir práticas clientelísticas na nomeação dos adjuntos e na própria efetivação dos professores públicos da Corte não invalida as análises que apontavam para as origens sociais de alguns professores, relacionando-as às classes empobrecidas da sociedade imperial.

lsso porque as relações de dependência e a troca de favores de toda a ordem se constituíam de relações de dois sentidos - complementares, porém desequilibradas - entre proprietários e não-proprietários, pessoas influentes e ilustres e desclassificados sociais, funcionários públicos e não-funcionários, senhores e homens livres e pobres. A rede de clientes e padrinhos, na sociedade imperial, não se limi- tava à relação senhores/escravos/senhores/agregados, mas abarcava inúmeras teias de relações sociais, não distinguindo classes e lugares sociais (Chalhoub, 2003).

As representações construídas pelo periódico de Alambary Luz, a despeito de alguns artigos que deixavam escapar práticas de apadrinhamento, disputas pessoais e picuinhas políticas entre os mestres, visavam fortalecer as imagens simbólicas dos professores como homens e mulheres honestos, ciosos, respeitáveis e, tal qual sacerdotes, conscientes de seus deveres e de sua missão pedagógica.

A idéia de sacerdócio, os sacrifícios em prol da instrução pública e das pequenas crianças, bem como a idéia de vocação, cobriam as representações sobre o ofício dos mestres, relacionando-os aos combatentes soldados que lutaram pela honra da pátria e pelo bem nacional. A vinculação à figura dos sacerdotes não se dava, contudo, sem razão. Tradicionalmente, os primeiros mestres no Brasil - os soldados de Cristo na Terra de Santa Cruz - provinham das ordens religiosas, principalmente jesuíta (Neves, 1973). Por outro lado, é preciso lembrar, com Antonio Nóvoa (1987), que o processo de estatização e a laicização da escola primária, desde fins do século XVIII no Ocidente, não prescindiu da influência religiosa e da moral confessional, no que se refere às disciplinas pedagógicas e às imagens do professor como missionário disposto a todos os sacrifícios em prol da instrução popular.

A relação entre o mestre-escola e o sacerdote, até pelo menos a primeira metade do século XIX, esteve vinculada ao fato de que os homens, entre os quais alguns padres, predominavam no exercício do magistério público. No entanto, a partir das décadas finais do século XIX, em relação à instrução pública primária na cidade do Rio de Janeiro, o número de

10. Códices da Instrução Pública: cód. 11.4 .36 e cód. 11.3.35, Arquivo Geral da Cidade do Rio de Janeiro.

11. A reprodução endógena e familiar do magistério também ocorria em Portugal, como pesquisou Nóvoa (1987), e na França dos oitocentos, conforme Jacques Ozouf (1973). 
professoras sofreu uma elevação surpreendente, acompanhando o aumento quantitativo das escolas oficiais. Em 1872, quando o censo contabilizou na cidade cerca de 270.000 habitantes (somando-se livres e escravos), havia 15 escolas públicas primárias rurais ou suburbanas, 10 masculinas e 5 femininas, e 32 urbanas, divididas na mesma proporção para ambos os sexos $^{12}$. Para essas escolas, o quadro de professores públicos primários, incluindo efetivos e auxiliares (adjuntos), era formado por 87 membros, sendo 49 homens e 38 mulheres. Em 12 anos, conforme dados do Relatório do Ministério do Império de 1884, o número de mulheres que atuavam como professoras públicas praticamente triplicou, chegando a ultrapassar o quantitativo dos homens: dos 197 mestres de escolas primárias, 107 eram do sexo feminino. Esses números indicam, claramente, a expansão da inserção das mulheres no trabalho docente da cidade, o que não significou o abandono das representações sobre a função missionária do professor e da professora primária no projeto de civilização das classes populares via instrução (Schueler, 2004).

A trajetória de um mestre-escola, relatada por Augusto Candido Xavier Cony como memória póstuma, ilustra bem a relação entre as vestes sacerdotais e sua presença na instrução pública primária ${ }^{13}$.

Antonio lgnácio Mesquita iniciou seus estudos no seminário para meninos pobres. Desejava ser padre. "Causa estranha e fatos imprevistos" - ao que parece, uma esposa e filhos - modificaram o destino do seminarista, que se tornou adjunto de escola pública, professor efetivo durante 15 anos. Pelas contas de Cony, o professor Mesquita ingressara no magistério da Corte por volta dos anos de 1857-1858.

Amigo das crianças, a elas ligado por "verdadeiros laços de família", ensinava-lhes os caminhos da moral e do trabalho morigerado. Após anos de infatigável serviço prestado ao Império, lamentava Cony, o professor Mesquita morreu como nascera - pobre -, deixando esposa e filhos dependentes da caridade públi- ca e da cotização dos mestres-escolas para o seu sustento.

0 exemplo de Antonio Mesquita, em que pese a sinceridade presente na homenagem de seu colega de profissão, servia bem aos propósitos de Augusto Cony ao publicar seu artigo demonstrar aos leitores a vida dura, sacrificante de um mestre dos filhos do povo. Nas palavras do articulista, tal era a "sorte de todo empregado público": um passado de atropelações, um presente atrofiado de necessidades, um futuro de miséria cotado à família ${ }^{14}$.

Em outro sentido, Costa e Cunha tratava da insuficiência do ensino primário na cidade e da precariedade dos métodos pedagógicos aplicados. Porém, tal estado de coisas não era de responsabilidade dos mestres-escolas, reiterava, concordando com Francisco Castilho. Os professores, pobres diabos, não possuíam tempo nem dinheiro para compra de livros e manuais que visassem aprimorar seus estudos, suas técnicas e suas metodologias de trabalho.

Augusto Cony concordava com as preleções de seu colega de ofício e redação. Ele próprio, professor público, precisava usar de vários expedientes para sobreviver, inclusive lecionar em escolas particulares da cidade - não referiu apenas que tal escola era de sua propriedade , o que prejudicava a sua dedicação à causa da instrução pública. Como ele, vários mestres-escolas trabalhavam no ensino particular no qual eram preferidos por representarem as "marcas oficiais" e a possibilidade de participar nas mesas de Exames Públicos ${ }^{15}$.

Porém, o professor, um herói da resistência, segundo Costa e Cunha, era capaz de superar todas as animosidades por meio de suas forças, seus desejos, seu patriotismo e seu

12. Em números absolutos, a Corte contava no ano de 1870 com 47 escolas públicas, 26 de meninos e 21 de meninas. A questão do processo de feminização da docência nos anos finais do século XIX, na Corte, foi mais detidamente discutida por Schueller (2004). Para 0 caso de São Paulo, consultar o trabalho de Jane Almeida (1998).

13. "Morte de um professor público". Augusto Candido Xavier Cony. Instrução Pública, Ano II, 27/07/1873, p. 250.

14. Id., Ibid., p. 250

15. "O Ensino Oficial e o Diretor da Escola Normal da Província do Rio de Janeiro". Instrução Pública, Ano I, 04/07/1872, p. 234. 
zelo. Por isso, argumentava contra os críticos, nem todos eram ignorantes ou concordavam com os "métodos rotineiros" que, em razão de condições adversas, eram obrigados a seguir.

Para que o ensino primário melhorasse no Império, era preciso, na opinião do professor, moralizar a população por meio da religião e implantar nos corações o amor à pátria. Como? Ensinando história e geografia nacionais, estudando mapas, desenhos e as modernas "lições de cousas" - sugeria, demonstrando não desconhecer os debates internacionais sobre novos métodos e materiais de ensino.

Porém, tais inovações, imprescindíveis para serem aplicadas nas escolas da Corte e do Império, dependiam de não poucas verbas públicas. Nas escolas do Rio de Janeiro, dizia, o dinheiro não chegava para comprar nem dicionários da língua materna!, ironizava o mestre-escola. $\mathrm{Na}$ sua própria língua, ferina e afiada, disparava:

Os professores ou pelo menos alguns dentre eles fazem o que devem e mais do que podem, mas por mais estudiosos, aplicados e laboriosos que sejam estes ou aqueles, envolvidos como se acham, por leis e regulamentos organizados por quem nunca penetrou numa escola; obrigados a ensinar programas de horas matematicamente reguladas e por métodos engendrados por quem não tem a necessária prática; assim coagidos, podem esses servidores da nação fazerem mais? ${ }^{16}$

Costa e Cunha não poupou ninguém na defesa que realizou dos professores públicos. Reformas autoritárias, metodologias decretadas de cima para baixo, por ministros que nunca penetraram em uma escola e não possuíam o savoirfaire, a prática do magistério, da qual os mestresescolas, aos trancos e barrancos, dominavam.

Após acusar o governo imperial de lidar com os professores tal qual "bodes expiatórios", o redator propunha que novos livros fossem adquiridos para os professores; que estes tivessem liberdade para escolher metodologias de ensino; que Escolas Normais, Conferências Pedagógicas,
Premiações aos melhores professores fossem instituidas pelo Estado imperial para melhorar a "sorte" do magistério e da instrução pública.

Além disso, em outros números do periódico, as críticas ao governo imperial e às suas práticas de nomeação, contratação e pagamento dos professores foram recorrentes. Em 1872, tendo sido aberto concurso para provimento de cadeiras de segundo grau primário, para as escolas públicas da cidade, não havia aparecido nenhum candidato. Isso ocorria, segundo testemunhava o periódico, pelo descrédito dos salários frente à exigência de maior quantidade de matérias e saberes para os cargos vagos:

Exigir o conhecimento de todas essas matérias, e o trabalho profissional, oferecendo em troca a obscuridade, e um ordenado de um conto e tanto, ou mesmo de dois contos de réis, é querer escolas de segundo grau no papel, só no papel, talvez para que o estrangeiro suponha, perlustrando os nossos regulamentos, que as temos e freqüentadas. ${ }^{17}$

Das escolas de papel, os professores passavam a desafiar o governo demonstrando o desprestígio e a posição pouco honrosa de suas funções na sociedade imperial, a despeito de sua importância para a construção da nação:

Em nosso país, não é preciso saber tanto para aspirar as mais altas posições; e ninguém porá parte de suas ambições, para arrastar a vida trabalhosa e inglória em um cantinho da cidade, lutando por satisfazer as suas primeiras necessidades, para merecer o título bem apreciado de mestre-escola.

Pobreza, austeridade, sacrifícios, sacerdócio e missão - eis algumas representações que os professores redatores buscavam construir sobre si mesmos, conformando identida-

16. "O Ensino Primário e seus Métodos", Costa e Cunha. Instrução Pública. Ano I, 26/05/1872, p. 50-51.

17. Id., Ibid, p. 50-51. 
des profissionais, que forjavam a agregação e a associação, a despeito das diferenças e da multiplicidade de concepções, experiências individuais e práticas de ensinar. Por meio dessas representações e desse processo de construção e reelaboração de identidades, os professores apresentaram-se como categoria profissional ao público leitor, ora por vias diretas, como nos exemplos e nas trajetórias pessoais que analisavam, ora por meio de temas diversos, ao abordarem os problemas educacionais e sociais que julgavam fundamentais.

Além disso, os mestres da Corte participaram ativamente no processo de constituição da profissão docente, fazendo-se professores, por intermédio da discussão pública e da produção coletiva de identidades profissionais, provisórias, móveis e contraditórias, as quais funcionavam como instrumento de agregação em torno da configuração da idéia do magistério como uma missão de fundamental função pública e social.

Revelavam, por outro lado e a despeito das críticas sobre sua suposta ignorância, - e ainda das representações sobre o "velho e atrasado" mestre-escola oitocentista - , conhecer a situação do ensino em outros países, as tecnologias da moderna pedagogia e as "idéias libe- rais do século". Apresentavam aos dirigentes do Estado, em contrapartida, algumas críticas, reivindicações e sugestões, as quais apontavam para idéias e pensamentos nem sempre coincidentes com os dos seus superiores.

Por meio da Instrução Pública - e de outros jornais especializados (que foram catalogados, embora não analisados neste estudo como, por exemplo: A Verdadeira Instrução Pública - 1871; Escola - 1877 a 1879; O Ensino - 1878; e ainda o Ensino Primário - 1884 a 1890)-, os mestres não apenas demonstravam que se dispunham a discutir os problemas educacionais, mas principalmente que não assistiam passivos às reformas do governo e, muito menos, que constituiam uma classe profissional amorfa e homogênea, alheia à formulação de opiniões próprias e aos debates existentes na sociedade em que viviam.

Demonstraram, sobretudo, que eram sujeitos no processo de constituição da profissão docente, construindo, reconstruindo e disputando identidades coletivas, as quais, em última instância, representavam a face contraditória das tentativas de controle estatal sobre a totalidade dos processos educativos, os homens, as mulheres, as crianças e os agentes da ação educativa.

\section{Referências bibliográficas}

ALMEIDA, J. Mulher e educação: paixão pelo possível. São Paulo: UNESP, 1998.

CATANI, D.; BASTOS, M. H. (Orgs.). Educação em revista: a imprensa periódica e a história da educação. São Paulo: Escrituras, 2002.

CHALHOUB, S. Machado de Assis historiador. São Paulo: Cia. das Letras, 2003.

NEVES, L. F. B. 0 combate dos soldados de Cristo na terra dos papagaios. Rio de Janeiro: Forense, 1978.

NÓVOA, A. Le temps de professeur: analyse socio-historique de le profession enseignante au Portugal. 2 volumes. Lisboa: INIC, 1987.

(Org.). Vidas de professores. Porto: Porto Editora, 1992.

A imprensa de educação e ensino: repertório analítico (séculos XIX e XX). Coleção Memórias da Educação. Lisboa: Instituto de Inovação Educacional, 1993. 
OZOUF, J. Nous les maitres d' Ecole. Autobiographies d'instituteurs de la Belle Epoche présenteés par Jacques Ozouf. Colecction Archives Gallimard Julliard. Paris: Juliard/Gallimard, 1973.

SCHUELER, A. F. Forma e culturas escolares na cidade do Rio de Janeiro: representações, práticas e experiências de profissionalização docente em escolas públicas primárias. Tese (Doutorado) - Universidade Federal Fluminense, Niterói. 2002.

. Notas sobre a feminização da docência: professoras primárias na cidade do Rio de Janeiro de fins do século XIX. Cadernos de Educação. Pelotas, ano 13, n. 22, jan./jun. 2004.

THOMPSON, E. A formação da classe operária inglesa: a árvore da liberdade. V. I. Rio de Janeiro: Paz e Terra, 1987.

VILLELA, H. A Imprensa Pedagógica e constituição da profissão docente: alguns embates. In: GONDRA, J. (Org.). Dos arquivos à escrita da história: a educação brasileira entre o Império e a República. Bragança Paulista: EDUSF, 2001.

. Da palmatória à lanterna mágica: a Escola Normal da Província do Rio de Janeiro entre o artesanato e a formação profissional (1868-1876). Tese (Doutorado)— Universidade de São Paulo, São Paulo, 2002.

Recebido em 08.07.05

Modificado em 03.03.05

Aprovado em 18.08.05

Alessandra Frota de Schueler é doutora em Educação pela Universidade Federal Fluminense. Atua como professora adjunta na Faculdade de Educação da Universidade do Estado do Rio de Janeiro (UERJ), na qual integra o Núcleo de Ensino e Pesquisa em História da Educação (NEPHE/UERJ). Leciona também na UNILASALLE/RJ. 